\title{
Medical Euphemisms' Ways of Formation and their Attitude towards Related Events
}

\author{
Abuzalova Mekhriniso Kadirovna, Gaybullaeva Nafisa Izzatullayevna
}

\begin{abstract}
The article focuses on the attitude of medical euphemisms towards relevant events in metaphor, metonymy, periphrases, meiosis, pronoun replacement, ellipse, antiphrasis, using the techniques of non-language foreign language. In some cases, mixed cases also occur. Among the methods used are metaphor, pronoun replacement, and medical terminology. Metaphorically, on the basis of imagery and likeness, the metonymy appears on the basis of the calling with another name, migration of meaning appears to call the parts of item on the basis of different names. Evidently, the evolution of the meaning is based on the meaning of the meaning.

Units of such units are subdivided into smaller units such as narrowing and chemotherapy. The name of the disorder in the hypo-hyperonomic relationship, the name of the body, the name of the physiological process, the speech, the quietness of the speech, the shameful, If such language units are in the hyphenation position, its hyperonimage refers to the event as a common name, and the information becomes neutral. The materials of the medical periodicals were analyzed.
\end{abstract}

Keywords : Euphemism, Phonetic Allergy, Metaphor, Metonymy, Peripheral Application, Antonym, Litotes, Antiphrasis, Ellipse.

\section{INTRODUCTION}

$\mathrm{E}_{\text {valuation is one of the most important factors in }}$ achieving speech culture. Closure of speech shortcomings, replacing its units with the environment and process according to the process were an issue raised by antiquity scholars. Particular attention is paid to the phenomenon of such philosophers as Aristotle, Cicero, and Quintilian. There were important requirements for such speeches; such as accuracy, clarity, reasonableness, meaningfulness, diversity, clarity, craving, imagination, short and humorous, authenticity. The significance of these signs on the formation of euphemism was reflected in BN Golovin and T. P. Grays. Scientists emphasized that failure to comply with the above requirements in the process of euphemism would lead to uncertainty, without confidence and doubtfulness.

For the first time in the Russian linguistics, the methods and methods of formation were investigated by $\mathrm{J}$. W. Warbot; the initial conclusions as to the appearance of double-faceted, descriptive expression, common nouns, transposition into the legs. L.A.Bulakhovsky, B.A.A.Larin, A.A.Reformatsky,

Revised Manuscript Received on October 15, 2019.

* Correspondence Author

Abuzalova Mekhriniso Kadirovna*, Doctor of Science, Professor of Uzbek Linguistic department, Bukhara State University

Gaybullaeva Nafisa Izzatullayevna, Doctorate student of Bukhara State University, nafisa.ped@mail.ru, (91) 4403370
B.V.Tomushevskiy have already stated some ideas about the origin of euphemism. Later on, Euphemisms Approach to Related Events In S.Vidlak studies, ephemera methods were specifically studied in LP Krisin's, V. Mosskin's research.

L. P. Krisin points out that the word euphemism is derived from a number of words that expresses the word as a common name, foreign words / terms, abbreviations, weakness, or inaccuracies of the phenomenon, as S.Vidlak points out that dysphemic character to replace the word in the language (because the negative impact of the negative words is less affected); (1); partial antonyms (eg use of false language instead of reality) (2); metaphorical use of the word (3). In addition, A. Dombrovskiy incorporates the phenomenon of phonemic algebra, metaphor, metonymy, paraphrase, antinomies, Lithia, antiphrasis, as well as the evolutionary method.

American scientists have also studied the methods of euphemism. The goal was to satisfy the needs of practical linguistics, such as the creation of the dictionary of euphemisms, enriching the definitive dictionary of euphemism. American dictionary linguists Dj.N. Nimen, KJ Jilberver, lists the ways in which euphemism is shaped in the dictionary:

1) Reproduction, in particular with Greek and Latin terms;

2) assignment of a general name;

3) method of naming in metonymy;

4) Method of metaphorical migration;

5) abbreviations.

Among the methods of euphonic coding, B.Uorren discovered the occurrence of reported word (3), metaphor (2), and meiosis (3).

In the course of our observations, we have seen that the most complete classification of methods for the manufacture of euphemist agents is reflected in the works of V.M. Mosquin. The subject of the scientist 's euphemism phenomenon, as a rule, is based on a portable meaning, and summarizes it as follows:

I. Based on the meaning migration:

1. Metonymic naming (in this method, B.V.Tomomovsky noted the origin of euphemism).

2. Metaphor.

3. Antiphrasis (reverse expression: use of aroma in the form of a fragrant smell for euphemist interpretation).

4. Pronouncing pronunciation with a word (A. Dombrovskoy called "phonetic allusion").

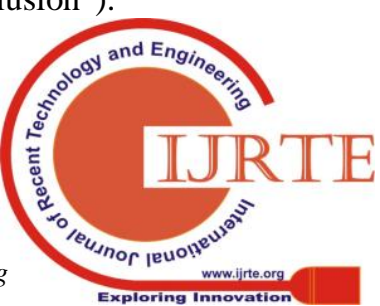


The word "paronymy coupling" is given by V.M.Moskvin in the near term, and it gives an excellent analysis of the ideas of A.A.Reformatsky, Dj.Nimen, K.Silver, S.Vidlak, L. A.Bulakhovskii .

II. Understanding the meaning of the meaning is:

1. Nominalization (alteration of language units with pronouns).

2. Hypernization (event, generalization of a subject, Moscow has defined this method as hyper naming). This method is characterized by a specific, distinctive feature of the subject (a); The words spoken by the speaker are made by means of the description (b) of the word that is obscure: to divide the child into one place.

3. Antonym (a metonymy).

4. Ellipsis.

Transfer from one species to another "(Aristotle). Usually, professions that have low prestige in the community tend to be: (Russian, technichka instead of ubshchitsa).

6. Synecdoche.

7. Meiosis - a weak expression of reality (in the place of snow is poor, hearing impaired).

III. By using the word in its proper sense:

2. Foreign words that are not native to language. A. A. Reformatsky asserts that this method of oral hypertension is more frequently encountered in the speech of medical personnel (for example, it is called Latin name).

Scientists, comparative studies based on Russian, English and Polish materials, show the metaphor as a metaphor for the metaphor, the most commonly used method of metaphor. Usually, human behavior is compared to animal movements; it creates a meaningful migration, so that speech is figurative. Polish evolutionist A.Dombrovskaya claims that $40 \%$ of mating is based on semantic derivation. Azerbaijani linguist Hosay Mahmudoglu Jabborov is a lexical for evolution (1); phraseology (2); grammatical path (3). The Kazakh linguist A.Kh. Akhmedov concludes on the ways of evaporation through literary art:

1) euphemist metaphor (cover-molding);

2) euphemist metonymy (coating substrate);

3) euphemist periphrases (cover coating);

4) euphemist symbol (cover symbol);

5) euphemist irony (cover-borne irony);

6) euphemist paraphrase (coincidental acne);

7) Euphemisms formed by means of other language elements (concealment of other language elements).

Below you will find the ways of creating medical euphemism on the basis of the analysis of the Uzbek language morphs.

Metonymy-based medical euphemisms are very much in Uzbek. For example: to stay silent. It does not matter if you choose to stay out of the ears ("Shifo-info", 2016. - No. 20, p. 16); rest disorder (in the sense of sleeping). Adult sleep disorders in the adult continue with apathy and lack of mood ("Diagnosis", 2015. - No. 37, p. 3); sexual life. This is due to the fact that most of the information about intimate life originates from early, from 16 to 17 years of age (not only for boys, but also for girls) ("Health Secrets", 2017. - No. 4, p.
1. Biblical phrases (including the term).

33). Metonymy is a type of event based on the fact that an event is the migration of the subject to the second one.

The interconnectedness of metonymy expressions is the use of an inducer for another expression based on its relevance. " Deafness is associated with hearing, sleep disorder, sleep behavior, sexual behavior, sexual desire, and action associated with needs, and therefore, the euphemisms in the above context are a metonymic euphemist unit.

The most commonly encountered metaphors are the euphemisms based on the way of creating euphemist instruments in the Uzbek language. "Metaphor is the use of a lexeme in the essence of events and phenomena to refer to something other than their own particulars and phenomena." For example: excessive weight. I want to make diet for overweight ("Shifo-info", 2017. - \# 39, p. 3); menstrual period. Menstrual state of menstrual cycle increases the development of osteoporosis ("Diagnosis", 2015. - No. 37, p. 4); weak man Sexual superiority, enthusiasm, self-confidence and other qualities of these people are higher than those of us who are worried about us (Shifo-info, 2016 - No. 19, p. 31); mental illness. People with mental illness are at first glance like a healthy person and can change from time to time (Shifo-info, 2018. - No. 2, p. 25); weight. Due to some obstacles in the ear canal, the outer and middle ear systems can not transmit an incoming ear signal to the inner ear.

This type of weigh can be treated surgically or in other common ways (Shifo-info, 2016. - No. 20, 16b). The similarity of symptoms in overweight obesity, the similarity of the phenomenon in the menopausal period, the similarity of one of the weak male male characteristics, the similarity of the mental illness to the psychological state of the mental illness, and the similarity of the severity of hearing impairment metaphorically is an example of the euphemist union formed.

There are also many types of medical evidences, which are based on uncertain interpretation of the meaning. One of these methods is hypernimation, that is, the general name of the object / reality. For example: hearing impairments. Those who suffer from hearing impairment will lose their ability to communicate with others (Shifo-info, 2016. - No. $20,15 b)$; limited communication capabilities. Access to various services and limited communication opportunities will affect the daily lives of these people (Shifo-info, 2016, No. 20, p. 15). There are various types of hearing disorders, one of which is deafness. Here, hypertonisation has occurred as a result of the deformed name of the disease under the general name of these diseases.

There is a large number of units of periphery (pictorial expression) in the medical euphemisms of the Uzbek language. "Illustrative expression is a solid combination of object, event and phenomenon, not by its own name, but by describing its essential characteristics: white gold - cotton, silver fiber - caps, captain of blue caps - mechanic, etc." 
For example: aged nursery. In addition, wrinkles on the skin increase wrinkles as a result of dehydration ("Shifo-info", 2017. - \# 39, p. 6); the first sign of age. Failure to do so is understood to be the first sign of physical disability or an aging old age ("Shifo-info", 2016. - No. 20, $15 \mathrm{~b}$ ); virginity of girls. The loss of conscience may not be conceivable, or may have been ruined in childhood without knowing it. ("Bekajon", 2017. - No. 11, p. 23); the second heart of a young man. This method removes the part of the adenoma directly from the second heart of the young man ("Shifo-info", 2016. - No. 20, § 47); male power. Male power is gradually disappearing and the tendency towards sexually explicitly decreases ("Shifo-info", 2016. - No. 19, p. 31). The examples in these examples are an example of an illustration.

The euphemisms derived from the use of the word in the Uzbek language have a large percentage of the evaporated layer. One form of this technique is based on the use of bibliographical expressions, in particular the use of medical terms, and the use of foreign words that are not in the second form. In fact, these two methods are one, but it is important to differentiate them. The only way to distinguish between these evaporation tools is to do one thing. It is based on the terminology of the word in terms of the terminology of the dictionary. Here is an example of such aphapemic expressions: The process of stopping maleship from yours (Greek andro men, Pausae) is a process related to the abolition of male characteristics (Shifo-info, 2016. - No. 19, p. 31); We read a lot of literature about erection (male sexuality) problems in men ("Health Secrets", 2017. - No. 4, p. 33);

There is a bad smell in the area of women suffering from vaginal inflammation (Shifo-info, 2016. - No. 20, p. 4). In order to feed the baby correctly, the nozzle isola should be placed on the mouth of the child. Only milk glands will be completely released from milk (Shifo-info, 2016 - No. 20, p. Alcohol consumption, hormonal and physical changes, non-admission of sexual freedom under the influence of education, surgical interventions, obesity, hypertension, and medication are also causes of erosion ("Health Secrets", 2017. - No. 4, p. 33); excessive levels of total cholesterol in the body can weaken men's potential (sexuality). The use of such units can serve as a single word for dysphame-like words, but it can be more sensitive to the listener, which is a shameful, embarrassing word, because the meaning of these words is not universal, but the reader understands the meaning of such a unit.

Among the medical euphemisms in the Uzbek language, it is commonly found that antiphrasis, nominalization (substitution of linguistic unions), ellipsis, synecdoche, meiosis (weak expression of reality) are used. We analyze the texts involved in the following patterns of morphology.

White spots (heading). Vitelego - white spots, has been known to human beings since ancient times, but they have been thought to be highly contagious, such as the myocardium. The suffering of leprosy and leprosy was severe. They persecuted them to distant places. Even the papyrus of ancient Egypt had written about it. According to
English scholars, Queen Cleopatra suffered from the same disease in recent years. Famous American singer Michael Jackson also suffered from this disease. Jackson did not take a single penny for treating it, and went straight into the White Sweat. This does not mean that the patient is neither pain nor frown. There are no melanin substances that give color to the skin during illnesses. Members of the HGM increase the number of anesthesiopes in the liver to eliminate the problems of the liver. That is why the patients refer to the doctor only when the appearance of the disease, white spots. The disease begins with the appearance of small pink or purple dots in the skin and develops around the chest, face, eyes and mouth, and neck limbs. Gradually, the smallest joints extend and join together.

As a result, it becomes a large "colorless field." The white spots are smaller, and then grown as a crown (A.Sattorov, "Tablet of Treatment" - 2017).

The words highlighted in this text are evocative. All of the units, such as the disease, the disease, were used instead of vitelego disease. As a result, the name of the disease has not been repeated or less used in the text. An example of the use of the submucosa in the name of the disease is nominalization (replacing language units with diathesis). In the text, the meaning of the word "white" is the same as euphemist; this unit also serves to describe those who are sick with this disease (leprosy) and create a flywheel. The combination of small pink or swollen dots gives information about the state of the disease by the method of malaria (weak expression of reality).

As we have seen, the above text describes the evolution of marijuana, which is based on diarrhea, mice and flies. He notes that the above-mentioned grammatical forms can serve as a means of expressing functional-semantic categories, such as mildness / courtesy, diminution, and evolution. When we examine the examples of medical workers, we were convinced that in the Uzbek language, these tools were also evocative.

\section{Result AND CONCLUSION}

The papere focuses on the attitude of medical euphemisms towards relevant events in metaphor, metonymy, periphrases, meiosis, pronoun replacement, ellipse, antiphrasis, using the techniques of non-language foreign language. In some cases, mixed cases also occur. Among the methods used are metaphor, pronoun replacement, and medical terminology. Metaphorically, on the basis of imagery and likeness, the metonymy appears on the basis of the calling with another name, migration of meaning appears to call the parts of item on the basis of different names. Evidently, the evolution of the meaning is based on the meaning of the meaning. Units of such units are subdivided into smaller units such as narrowing and chemotherapy. The name of the disorder in the hypo-hyperonomic relationship, the name of the body, 
the name of the physiological process, the speech, the quietness of the speech, the shameful, If such language units are in the hyphenation position, its hyperonimage refers to the event as a common name, and the information becomes neutral. The materials of the medical periodicals were analyzed.

\section{REFERENCES}

1. Varbot J.J. Taboo // Russian language: Encyclopedia. - M., 1979.

2. BulakhovskyL.A. Introduction to Linguistics. Ch. 2. - M., 1953.

3. Moskvin V.P. Evaluation of the evolution of the lexic system. Volgograd, 1999 ;

4. Krysin JI.P. Euphemism and sovereignty of Russian speech // Russian language at the end of XX century (1985-1995). - M., 1996. - S. 400-402.

5. Dzhabbarov Khasan Mahmud Ogly. Taboos and euphemism in Azerbaidjan language. PhD dissertation. - Baku, 1972.

6. Akhmetov A.Turkic folklore taboos and euphemism. PhD dissertation. Almaty, 1995 